\title{
A Communication Efficient Framework for Soil Moisture Monitoring using Wireless Sensor Networks
}

\author{
Dr.L.S.Jayashree \\ Professor, Department of IT \\ Kumaraguru College of Technology
}

Coimbatore-641 006

\author{
R.Manju Priya \\ Final B.Tech student \\ Kumaraguru College of Technology \\ Coimbatore-641 006 \\ V.K.Yamini \\ Final B.Tech student \\ Kumaraguru College of Technology \\ Coimbatore-641 006
}

\begin{abstract}
Among the numerous numbers of applications the viability of wireless sensor networks have been thought about, environmental monitoring constitutes an important field of application. Given the severity of potential climate changes and its effect on the environment, it is a domain where the use of sensor networks can have great impact and as such, is getting more and more attention. The world we live in is currently undergoing dramatic changes at a global scale, i.e., global warming. Most of the time, environmental scientists cannot precisely answer questions regarding the cause and effects, mainly because of the lack of adequate data, given the multifaceted nature of the problem. Specifically, the challenge lies in developing viable techniques to collect and analyze large volumes of spatial and temporal observations of environmental parameters. An easy-to-deploy-and-configure pervasive WSN (Wireless Sensor Network) can be of great help to meet this objective. This paper discusses a framework for wireless sensor networks designed to capture and monitor surface soil moisture level - one of the key contributors of climate change modeling. The data collected could be used for building various models that could enhance our understanding about the effects of climate change on agricultural farms. In a crop field, this data can also be used to prepare effective irrigation schedules; dry situations can be alarmed and adequate irrigation can be done just on time. The paper proposes a communication efficient framework for collecting spatio-temporal observations of surface soil moisture. The proposed work prepares a moisture distribution map that is useful to understand the spatially and temporally varying patterns of soil moisture in the area of interest.
\end{abstract}

The full text of the article is not available in the cache. Kindly refer the IJCA digital library at www.ijcaonline.org for the complete article. In case, you face problems while downloading the full-text, please send a mail to editor at editor@ijcaonline.org 